\title{
同時観測による船位決定と誤差の処理 I
}

\author{
広田

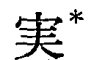 \\ Position Fix at Sea through Simultaneous Observations \\ and Stochastic Adjustment of Errors-I
}

M. Hirota

\begin{abstract}
Navigators may obtain four or more position lines by star sights at night or twilight. Then they can determine the most probable position through calculation based on the least square method. The writer gives formulas for position fixing and division of errors into a correction term and accidental errors.

Position fixing by calculation is rigorous and free from personal prejudice, but the calculation is rather complicated, and does not suit navigators' routine work. The writer explains a geometrical method for determining approximately the most probable position and a simple computation for correction term and estimation of standard deviation.

Navigators can find their. own observation errors from their sights at sea.

\section{1.は し がき}

夜間天測その他で 4 本以上の位置の 線を得たとき， 最小自乗法の処理によつて，最確船位を 得，定差及び偶差の分離を行ならことができる。ここではその計算式を与え，誤差について考察 を加える。

計算による最確船位決定は確定的で，個人による差の混入する機会はないが，計算誤りもあり 得るし，又計算そのものもかなり面倒で，海上に於ける実務に不向きである。それ故，幾何学的 に概略の最確船位を求める方法を考察し，これを用いて，定差及び偶差を見積る方法を与えた。 これによれば，海上に於ける天測のデータから，各人の測定精度を調べることもできよう。

\section{2. 天測による位置の線の方程式}

一つの天体の測定高度と，船の推定位置におけるその天体の計算高度及び計算方位より得られ る位置の線を考察する。

推定船位を原点にとつて，北に $y$ 一軸，東に $x$ 一軸をとる。方位は北を $0^{\circ}$ と，右畐りに $360^{\circ}$ までとする。この時推定船位に近い接点における天体の等高度円の接線の方程式は

$$
x \sin z+y \cos z=I
$$

ここに

$z$ : 計算方位
\end{abstract}

*神戸商船大学（神戸市東灘区本庄町深江） 
$I=a_{0}-a_{\mathrm{c}}$ (分)

$y:$ 緯度の差 $\Delta l$ (分)

$x=\Delta L \cdot \cos l, l$ : 推定位置の緯度

$\Delta L:$ 経度の差 (分)

$I$ をインターセプトと呼ふ。上記の式は次に示す 場合使用できない。

（1）推定船位が地球の両極に近い場合

（2）測定高度が $90^{\circ}$ に近い為，等高度円の半径が 小さく接線を以て円周を近似できない場合，及 計算方位が真方位と大きな誤差を持つ場合

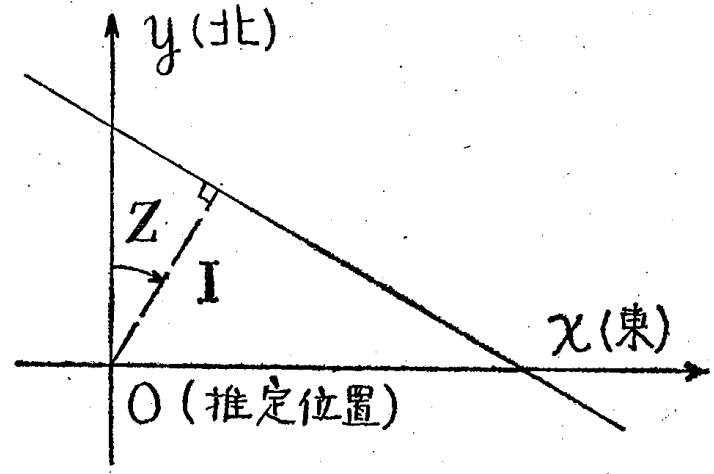

第 1 図 位置の線

(3) 高度が $0^{\circ}$ に近র，測定高度の修正值が正確に得られない場合

\section{3. 位置の線が 4 本以上のときの最確船位}

同時観測と言つても $n$ 個の観測には時間のズレがあるが，各観測時刻ごとの推定位置を用いて 高度計算すれば， $n$ 本の位置の線は総て同じ形式の方程式で与えられる。[註1]

$$
x \sin z_{i}+y \cos z_{i}=I_{i} \quad(i=1,2, \cdots \cdots, n)
$$

ここで最確船位 $\left(x_{0}, y_{0}\right)$ ，及び個人差等に起因する定差（補正項） $I_{0}$ を考え，これらを位置の 線の式に代入して得られる残差を $e_{i}$ とすると

$$
-e_{i}=x_{0} \sin z_{i}+y_{0} \cos z_{i}-I_{0}-I_{i}
$$

これを観測方程式と呼ぶ。次に最小自乗法によって残差平方和を最小にするごとく $x_{0}, y_{0}, I_{0}$ を定める。即ち

$$
\frac{\partial}{\partial x_{0}} \sum_{i} e_{i}{ }^{2}=0, \quad \frac{\partial}{\partial y_{0}} \sum_{i} e_{i}{ }^{2}=0, \quad \frac{\partial}{\partial I_{0}} \sum_{i} e_{i}{ }^{2}=0
$$

より，正規方程式は

$$
\begin{aligned}
& x_{0} \sum \sin ^{2} z_{i} \quad+y_{0} \sum \sin z_{i} \cos z_{i}-I_{0} \sum \sin z_{i}=\sum I_{i} \sin z_{i} \\
& x_{0} \sum \sin z_{i} \cos z_{i}+y_{0} \sum \cos ^{2} z_{i} \quad-I_{0} \sum \cos z_{i}=\sum I_{i} \cos z_{i} \\
& x_{0} \sum \sin z_{i} \quad+y_{0} \sum \cos z_{i} \quad-I_{0} \cdot n \quad=\sum I_{i}
\end{aligned}
$$

この連立方程式を解けば，最確船位 $\left(x_{0}, y_{0}\right)$ 及び定差 $I_{0}$ が得られる。

\section{4. 計 算 式}

(1)式に於て，各項，各係数を次の如く置く

$$
\begin{array}{lll}
a_{11}=\sum_{i} \sin ^{2} z_{i} & a_{12}=a_{21}=\sum_{i} \sin z_{i} \cos z_{i} & b_{1}=\sum_{i} I_{i} \sin z_{i} \\
a_{22}=\sum_{i} \cos ^{2} z_{i} & a_{13}=a_{31}=\sum_{i} \sin z_{i} & b_{2}=\sum_{i} I_{i} \cos z_{i} \\
a_{33}=n & a_{23}=a_{32}=\sum_{i} \cos z_{i} & b_{3}=\sum_{i} I_{i}
\end{array}
$$

このとき，正規方程式は次のごとく表現される。

$$
\begin{array}{r}
\left.\begin{array}{r}
a_{11} x_{0}+a_{12} y_{0}+a_{13}\left(-I_{0}\right)=b_{1} \\
a_{21} x_{0}+a_{22} y_{0}+a_{23}\left(-I_{0}\right)=b_{2} \\
a_{31} x_{0}+a_{32} y_{0}+a_{33}\left(-I_{0}\right)=b_{3}
\end{array}\right\} \\
\text { ここで }\left|\begin{array}{lll}
a_{11} & a_{12} & a_{13} \\
a_{21} & a_{22} & a_{23} \\
a_{31} & a_{32} & a_{33}
\end{array}\right| \neq 0 \text { とする。 }
\end{array}
$$


なぜなら，少くとも異る方向に 4 個以上の天体を選ぶことを条件としているからである。これら を解くと，次式が得られる。

$$
\begin{aligned}
& \left.\begin{array}{rl}
x_{0} & =c_{11} b_{1}+c_{12} b_{2}+c_{13} b_{3} \\
y_{0} & =c_{21} b_{1}+c_{22} b_{2}+c_{23} b_{3} \\
-I_{0} & =c_{31} b_{1}+c_{32} b_{2}+c_{33} b_{3}
\end{array}\right\} \\
& \text { ここに }\left(\begin{array}{lll}
c_{11} & c_{12} & c_{13} \\
c_{21} & c_{22} & c_{23} \\
c_{31} & c_{32} & c_{33}
\end{array}\right)=\left(\begin{array}{lll}
a_{11} & a_{12} & a_{13} \\
a_{21} & a_{22} & a_{23} \\
a_{31} & a_{32} & a_{33}
\end{array}\right)^{-1} \text { である。 }
\end{aligned}
$$

筆算等でこれらの計算を行ならには，計算誤りをチエツクできる定式化されたフオームがあ り，文献例えば[1]に詳しい。

\section{5. 誤差の処理}

残差平方和 $S_{e}$ は計算で求めた $x_{0}, y_{0}, I_{0}$ を観測方程式に代入して得てもよい。

$$
S_{e}=\sum_{i} e_{i}^{2}=\sum_{i}\left(x_{0} \sin z_{i}+y_{0} \cos z_{i}-I_{0}-I_{i}\right)^{2}
$$

であるが，次のように計算した方が簡単である。(1)式を考慮して

$$
\begin{aligned}
& S_{e}=\sum x_{0} \sin z_{i}\left(x_{0} \sin z_{i}+y_{0} \cos z_{i}-I_{0}-I_{i}\right)+\sum y_{0} \cos z_{i}\left(x_{0} \sin z_{i}+y_{0} \cos z_{i}-I_{0}-I_{i}\right) \\
& -\sum I_{0}\left(x_{0} \sin z_{i}+y_{0} \cos z_{i}-I_{0}-I_{i}\right)-\sum I_{i}\left(x_{0} \sin z_{i}+y_{0} \cos z_{i}-I_{0}-I_{i}\right) \\
& =-\sum I_{i}\left(x_{0} \sin z_{i}+y_{0} \cos z_{i}-I_{0}-I_{i}\right)=-x_{0} \sum I_{i} \sin z_{i}-y_{0} \sum I_{i} \cos z_{i}+I_{0} \sum I_{i}+\sum I_{i}{ }^{2} \\
& \therefore \quad S_{e}=\sum I_{i}^{2}+I_{0} b_{3}-y_{0} b_{2}-x_{0} b_{1}
\end{aligned}
$$

残差 $e_{i}$ の原因となる誤差は，各観測ごとに独立で, 平均 0 , 分散 $\sigma$ の正規分布するものと すれば，分散の不偏推定值合は次式で与えられる。

$$
\hat{\sigma}^{2}=S_{e} /(n-3)
$$

従来の最小自乗法で法 $\hat{\sigma}^{2}$ が $\sigma^{2}$ に一致するものとして扱つていたが，これは $n-3$ が充分大き 、場合にのみ近似的に成立することである。 $S_{e} / \sigma^{2}=(n-3) \hat{\sigma}^{2} / \sigma^{2}$ は自由度 $(n-3) の \chi^{2}$ 分 布をなすことが期待できるから，例えば信頼度を $(1-2 \alpha)$ ）と定めて $\sigma^{2}$ の信頼区間を

$$
\frac{S_{e}}{\chi^{2}(n-3, \alpha)} \leqq \sigma^{2} \leqq \frac{S_{e}}{\chi^{2}(n-3,1-\alpha)}
$$

と推定することができる。しかしながら，海上での一連の観測では $n=5$ 以上の測定を行なうこ とは希であつて，自由度が小さすぎて推定区間が大きく，実用にならないであらう。普通の場合 には，自らの希望する值に $\sigma^{2}$ を仮設するか，文献 [2]等で与えてある数值をとるか，或唗 来のデータより推定するかした $\sigma^{2}$ の值を，上記の信頼区閒内にあることを確めてから，使用す ればよい。ここにでてくる第一種危険率 $\alpha$ をどうきめるかは改めて考察したい。

$\sigma^{2}$ の仮設検定された值を $\sigma_{0}^{2}$ とすれば， $x_{0} ， y_{0} ， I_{0}$ に対して次式が成立する [1]。

$$
\sigma_{x \theta}^{2}=c_{11} \sigma_{0}^{2}, \quad \sigma_{y 0}^{2}=c_{22} \sigma_{0}^{2}, \quad \sigma_{10}^{2}=c_{33} \sigma_{0}^{2}
$$

ここに

$$
c_{11}=\frac{\left|\begin{array}{ll}
a_{22} & a_{23} \\
a_{32} & a_{33}
\end{array}\right|}{D}, c_{22}=\frac{\left|\begin{array}{ll}
a_{33} & a_{31} \\
a_{13} & a_{11}
\end{array}\right|}{D}, \quad c_{33}=\frac{\left|\begin{array}{ll}
a_{11} & a_{12} \\
a_{21} & a_{22}
\end{array}\right|}{D}, \quad D=\left|\begin{array}{lll}
a_{11} & a_{12} & a_{13} \\
a_{21} & a_{22} & a_{23} \\
a_{31} & a_{32} & a_{33}
\end{array}\right| \ldots \ldots \ldots \ldots \ldots(9)
$$

ここに与えられた $\sigma_{x 0}, \sigma_{y 0}$ を径とする棈円を画くならば，内部に於ける船位の存在確率が $1-1 / \sqrt{ } \overline{\boldsymbol{\epsilon}}=0.393$ となる。この棈円は最小面積の誤差圏ではないが, .一般に多数の位置の線を 得る場合, 全方位をほぼ等分割する向きに天体を選ぶよう努力するので, 最小面積誤差圈が円に 
近いことが多く，大きな差はない。実用的には $\sqrt{\left(\sigma_{x 0}{ }^{2}+\sigma_{y 0}{ }^{2}\right) / 2}$ の半径を有する円を作図して もよいであろう。50\%，95\%誤差圈その他については，径を1.17倍，2.45倍等に伸することによ つて得られ，これは従来の理論と同じである。

\section{6. 定差を考慮することの幾何学的意味}

定差を除去する目的で，ほぼ反方位の天体の位置の線の交角の二等分線を用いる方法がある。 これを厳密化したものが, 定差を考慮した最小自乗法の計算である。

$n$ 本の位置の線を得たとき，あらゆる二等分線を求めれば ${ }_{n} C_{2}$ 本である。定差を除去する目的 では，ほぼ反方向の組み合せが価值高く，ほぼ同方向が殆んど無価值である。計算によると，等 しい精度を持つ二つの位置の線の二等分線の精度は $\sqrt{2} \sin \left(\left(z_{i}-z_{j}\right) / 2\right)$ 倍になる。〔2]それ故 二等分線の位置の線の残差に精度に比例する重みを付けて最小自乗法を行なえばよい。

今, 2 本の位置の線吕

$$
\begin{aligned}
& x \sin z_{i}+y \cos z_{i}=I_{0}+I_{i} \\
& x \sin z_{j}+y \cos z_{j}=I_{0}+I_{j}
\end{aligned}
$$

で与えられたとする。これらは標準型であるから，定差 $I_{0}$ を除き得る組み合せを取つて得た二 等分線注次式で与光られる。

$$
x\left(\sin z_{i}-\sin z_{j}\right)+y\left(\cos z_{i}-\cos z_{j}\right)=I_{i}-I_{j}
$$

この式は標準型でない。この二等分線の向きを $\theta$ とすると（ $\theta$ は北より右腼りに測る）

$$
\begin{aligned}
\tan \theta & =-\frac{\cos z_{i}-\cos z_{j}}{\sin z_{i}-\sin z_{j}}=\tan \frac{z_{i}+z_{j}}{2} \\
\therefore \quad \theta & =\left(z_{i}+z_{j}\right) / 2 \text { 又沙 }\left(z_{i}+z_{j}\right) / 2+180^{\circ}
\end{aligned}
$$

即ち，二等分線の向きは天体の方位を二等分する方位である。次に

$$
\left(\sin z_{i}-\sin z_{j}\right)^{2}+\left(\cos z_{i}-\cos z_{j}\right)^{2}=4 \sin ^{2}\left(z_{i}-z_{j}\right) / 2
$$

であるから，二等分線の式を標準型に直して

$$
x \frac{\sin z_{i}-\sin z_{j}}{2 \sin \left(z_{i}-z_{j}\right) / 2}+y \frac{\cos z_{i}-\cos z_{j}}{2 \sin \left(z_{i}-z_{j}\right) / 2}=\frac{I_{i}-I_{j}}{2 \sin \left(z_{i}-z_{j}\right) / 2}
$$

最確值 $x_{0}, y_{0}$ を大れたときの残差を $E_{i j}$ とし，これに $\left(2 \sin \left(z_{i}-z_{j}\right) / 2\right)^{2}$ の重みを付けて残 差平方和を作ると

$$
\begin{aligned}
& S_{E}=\sum_{i}^{i>j} \sum_{j}^{j}\left(2 \sin \frac{z_{i}-z_{j}}{2}\right)^{2} \cdot E^{2}{ }_{i j} \\
& =\sum_{i}^{i>j} \sum_{j}^{j}\left\{x_{0}\left(\sin z_{i}-\sin z_{j}\right)+y_{0}\left(\cos z_{i}-\cos z_{j}\right)-\left(I_{i}-I_{j}\right)\right\}^{2} \\
& \frac{1}{2} \frac{\partial}{\partial x_{0}} S_{E}=\sum \sum\left(\sin z_{i}-\sin z_{j}\right)\left\{x_{0}\left(\sin z_{i}-\sin z_{j}\right)+y_{0}\left(\cos z_{i}-\cos z_{j}\right)-\left(I_{i}-I_{j}\right)\right\} \\
& \left.=x_{0} \sum \Sigma\left(\sin z_{i}-\sin z_{j}\right)^{2}+y_{0} \sum \sum\left(\sin z_{i}-\sin z_{j}\right)\left(\cos z_{i}-\cos z_{j}\right)-\sum \sum\left(\sin z_{j}-\sin z_{j}\right)\left(I_{i}-I_{j}\right)\right\} \\
& =x_{0}\left\{(n-1) \sum \sin ^{2} z_{i}-2 \sum \sum \sin z_{i} \sin z_{j}\right\}+y_{0}\left\{(n-1) \sum \sin z_{i} \cos z_{i}-2 \sum \sum \sin z_{i} \cos z_{j}\right\}
\end{aligned}
$$

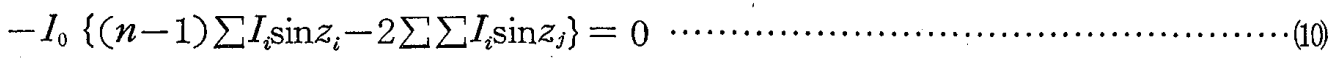

さて(1)式より

$$
x_{0} \sum \sin z_{i}^{2}+y_{0} \sum \sin z_{i} \cos z_{i}-I_{0} \sum \sin z_{i}=\sum I_{i} \sin z_{i}
$$

$x_{0} \sum \sin z_{i}+y_{0} \sum \cos z_{i}-I_{0} \cdot n=\Sigma I_{i}$

(11)式を $n$ 倍して(12)式を代入して $I_{0}$ を消去すると

$x_{0}\left\{n \sum \sin ^{2} z_{i}-\sum \sin z_{i} \sum \sin z_{i}\right\}+y_{0}\left\{n \sum \sin z_{i} \cos z_{i}-\sum \sin z_{i} \sum \cos z_{i}\right\}$ 


$$
\begin{aligned}
& =n \sum I_{i} \sin z_{i}-\sum I_{i} \sum \sin z_{i} \\
& \therefore \quad x_{0}\left\{(n-1) \sum \sin ^{2} z_{i}-\sum_{i}^{i \neq j} \sum_{j} \sin z_{i} \sin z_{j}\right\}+y_{0}\left\{(n-1) \sum \sin z_{i} \cos z_{i}-\sum^{i \neq c} \sum \sin z_{i} \cos z_{j}\right\} \\
& =(n-1) \sum I_{i} \sin Z_{i}-\sum_{i}^{\neq} \sum I_{i} \sin z_{j}
\end{aligned}
$$

(10)，(13)恃全く同じ式である。 $y_{0}$ についても同様である。

以上の結果より，最小自乗法で定差を考慮するこ との幾何学的意味は明瞭になつたであろら。又逆に 二等分線を用いる位置の決定に注, 始めの位置の線 が 4 本以上必要なことも判る。

\section{7. 幾何学的作図法}

定差を考慮して最小自乗法を行なつたとき，計算 によつて最確位置が与えられるが，計算が複雑で海 上の実務には不向きであるし，計算䛊りによつて誤 つた判断を下す可能性もある。ところで 6 . で示す ところによれば，二等分線を作つて，注市方位に 近い組み合せから得たものを重視し，ほぼ同方位に 近い組み合せより得たものを無視するるこによつ て, 幾何学的に概略の最確船位を決定することがで きる。

凡ゆる位置の線に天体の向きを示す知印を付け， 方位差角注常に劣角をとることにすれば，方位差角 は図 2 の如く与えられる。次に重みを表 1 に与え る。これらより方位差角が $120^{\circ} \sim 90^{\circ}$ を越えて小さ くなると，重みは急激に小さくなることが判る。こ のことから次のように概略位置を定める作図の方針 を定めることができよう。
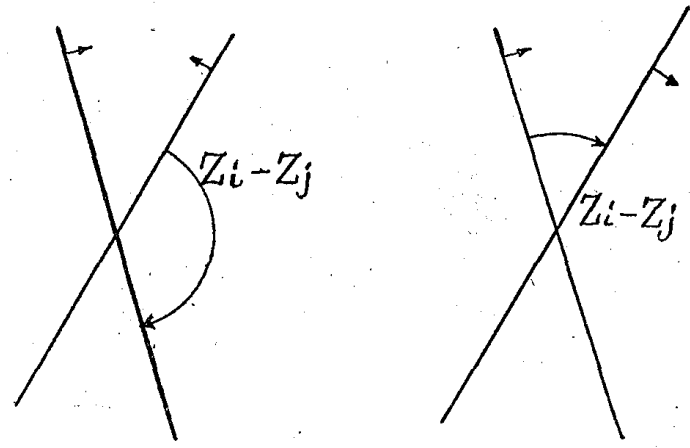

\begin{tabular}{|c|c|}
\hline 方位角差 & 重 み \\
\hline$\theta^{\circ}$ & $\sin ^{2} \theta / 2$ \\
\hline 180 & 1.000 \\
\hline $\begin{array}{l}150 \\
135 \\
120\end{array}$ & $\begin{array}{l}0.933 \\
0.854 \\
0.750\end{array}$ \\
\hline 90 & 0.500 \\
\hline $\begin{array}{l}60 \\
45 \\
30\end{array}$ & $\begin{array}{l}0.250 \\
0.146 \\
0.067\end{array}$ \\
\hline 0 & 0.000 \\
\hline
\end{tabular}

第 2 図 方位角差 第 1 表 重 み

[原則]

I．位置の線の本数が 4 程度のとき

11. 交角の小さいものから順に交点に番号を付け，交角が $60^{\circ}$ 又は $90^{\circ}$ になつたら止める。

12. 番号順に，方位角差が鈍角の交点に対して二等分線を記入し，少くとも三本を得る。

13. 順位の小さい二等分線を重視しながら，最確位置をきめる。（三角形が得られたときは， 各辺からその辺の長さに比例する距雄にある三角形内の点をとる。又必要があれば重みに対 する修正を加觉る。)

II. 位置の線が多数あるとき。

方位角差が $180^{\circ} \sim 120^{\circ}$ （得られないときはもつと小さくてもよい）の組み合せを選び出 し，二等分線を作図して，これらから最確位置をきめる。

III．異つた位置がともに最確位置の如く見えるとき。

31. それらの点より，凡ゆる位置の線に垂線を下し，その長さを $I_{0 i}$ とする。（符号はインタ 一セプトと同じ) 
32. $S_{e}=\sum_{i=1}^{n} I_{0 i}{ }^{2}-\left(\sum_{i=1}^{n} I_{0 i}\right)^{2} / n$ をを計算し，最小の $S_{e}$ を与える点を最確位置とする。

この原則に基づいて最確位置を求めた作図例を図 $3 ， 4$ 亿示す。

図 3 (a)は原則 I によつて作図したもの で，黒点江概略の最確位置を示す。同(b) は本数が多いので原則川によつて作図し た。最確位置は常識どおりほぼ位置の線 の交点の重心附近にある。

図 4 (a) は同方向及び反方向の二本の位 置の線の組み合せの場合である。このよ うな場合，最確位置は四辺形の内部にあ るとは限らない。同(b)は同方向の組み合 せで，最確位置は不明確である。計算に よると確定するが，(8)式によつて誤差が 大きいことが示されている。

\section{8. 簡易 集計 法}

最小自乗法の計算酒面倒であるが，将 来電子計算機等で計算が行ない得るな ら， $x_{0}, y_{0}, I_{0}, S_{e}$ 等計算で求めた方が
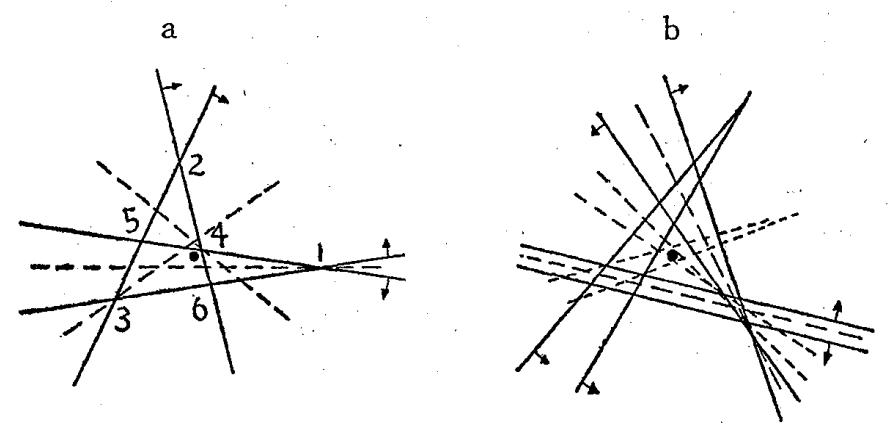

第 3 図 一般的な作図例(a) 4 本のとき，(b) 6 本のとき

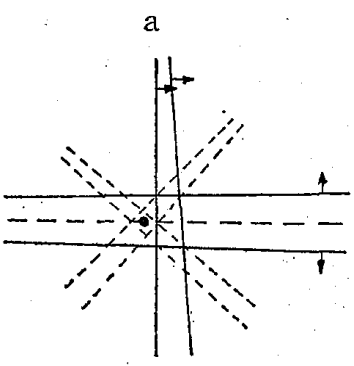

$\mathrm{b}$

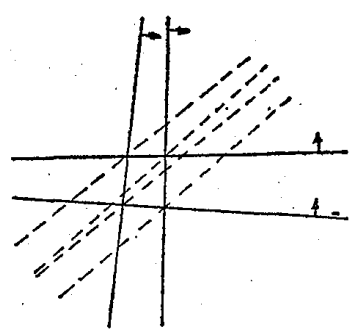

第 4 図 特殊な結果の例(a) 4 角形の外にでるとき, (b)不定のとき

よい。幾何学的に概略の $x_{0} ， y_{0}$ を求めた場合は次のように整理した方がよいであろう。

1. 推定船位が最確位置に一致していれば， $x_{0}=y_{0}=0$ であるから(12)式より判るように，補正值 $I_{0}$ は次式で与えられる。

$$
I_{0}=-\frac{1}{n} \sum I_{v_{i}}
$$

作図で求めて最確位置より，位置の線までの距離を $I_{0_{i}}$ とし（天体の方位と反対にあるとき 正)，これらの平均に負号を付ければよい。

2. 最確位置が正しいかどうかをチエックするには次のようにすればよい。最確位置に於る残差 $e_{i}$ の代数和は 0 であるから

$$
S_{e}=\sum e_{i}^{2}=\sum I_{i 0}{ }^{2}-\left(\sum I_{i 0}\right)^{2} / n=\sum I_{i 0}{ }^{2}-n I_{0}{ }^{2}
$$

を計算し，近傍の点と比較して， $S_{e}$ が最小であればよい。

3. 残差平方和 $S_{e}$ から，この天測に於ける $\sigma^{2}$ の不偏推定值 $\hat{\sigma}^{2}$ が得られる。 $S_{e}$ 又は $\hat{\sigma}^{2}$ が異 常に大きければ，測定又は計算に失敗があつたものと考えられる。（どの程度から異常と考え るかは次回に述べたい)

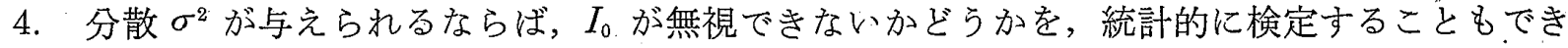
る。

5. $I_{0}$ を集め，これらを昼間，薄明，夜間，天候，海域等に分類して平均值を求めることによ つて，各人の補正項を得ることができる。〔〔註 2]

6. $S_{e}$ を集め，これから $\sigma^{2}$ を推定するに沙次のようにすればよい。 $m$ 組のデータ を集めたと き，各組が $n_{i}$ 本の位置の線で構成されているならば 
$S_{e t}=\sum_{k=1}^{m} S_{e k}, \quad N=\sum_{k=1}^{m}\left(n_{k}-3\right)$

を求め， $\chi^{2}$ 分布を用いて区間推定する。

$\frac{S_{e t}}{\chi^{2}(N, \alpha)} \leqq \sigma^{2} \leqq \frac{S_{e t}}{\chi^{2}(N, 1-\alpha)}$

ここに信頼度は $1-2 \alpha$ である。

\section{9. 結 び}

このあと，異常に大きい補正項 $I_{0}$ 及異常に大きい残差平方和 $S_{e}$ を得た場合の処理が残る。 異常の判断は何を規準とすべきかが最も問題になる。尚海上に於ける実際のデータについてもし らべてみたい。

\section{参 考、文 献}

[1] 宮本：詿差諭及び計算法

〔2]鮫島：船位誤差論

〔註 1 ] $n$ 個の観測を行ならとき，時刻にズレ があるにも拘らず，最終観測時の推定位置の みを用いて高度計算を行ならときは，位置の 線を作図する時に転移する必要がある。或は 又, 計算によって転移の終つた位置の線を求 めてもよい。

$i$ 番目の天測を行なつたときの推定位置を 原点とする座標系を $x, y$ とし，この原点よ り針路 $C_{0}$ て $D_{i}$ 浬航走した推定位置を高度 計算に於ける仮の推定位置とし，これを原点 とする $x, y$ 座標系を考えるとき, 任意の点 で次式が成立する。

$$
\begin{aligned}
& x=X+D_{i} \sin C_{0} \\
& y=Y+D_{i} \cos C_{0}
\end{aligned}
$$

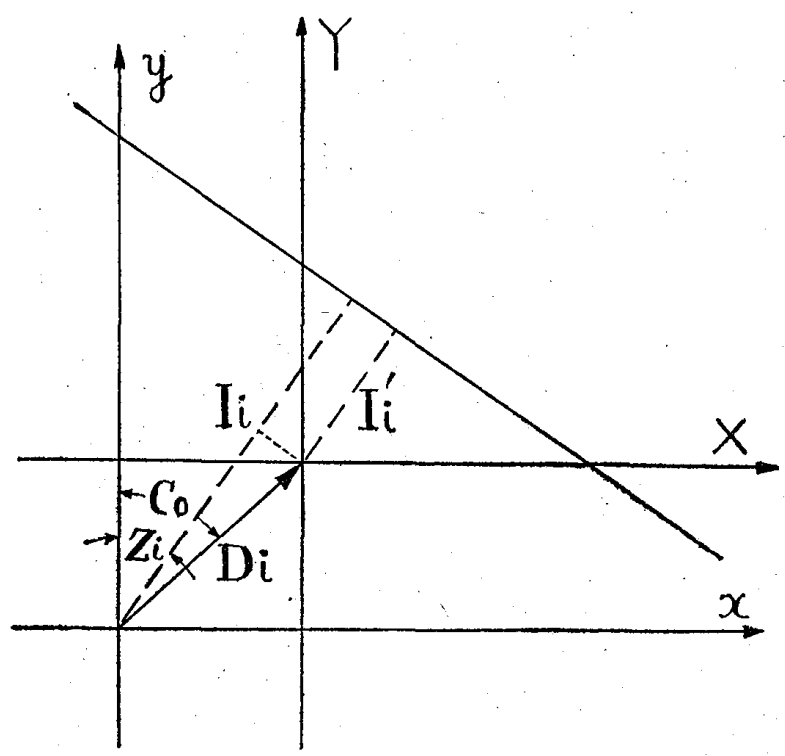

第 5 図 位置の線の転移

天測による位置の線は推測位置に無関係に正しいものが得られる。観測位置に於て

$$
x \sin z_{i}+y \cos z_{i}=I_{i}
$$

が得られるから， $x, y$ を消去して， $X, Y$ 座標系に移した位置の線の方程式は

$$
X \sin z_{i}+Y \cos z_{i}=I_{i}^{\prime}
$$$$
I_{i}^{\prime}=I_{i}-D_{i} \cos \left(z_{i}-c_{0}\right)
$$

これが転移された位置の線の方程式である。

〔註 2 】 $I_{0}$ の見積りには常に誤差があり，必ずしも一様ではない。正確には，1/C 38 に逆比例する重みを 付けて平均をとらなければならない。全方位を等分する方位に $n$ 個の天体を選しだときは， $c_{33}=1 / n$ にな ることが簡単に証明でき，この時の $I_{0}$ の精度は最も高い。他の場合は繁雑な計算によつて求められる。 $1 / c_{33}$ を有効反覆数と呼ぶ。 